\title{
GMR
}

\section{Role of VEGF gene polymorphisms in the clinical outcome of non-small cell lung cancer}

\author{
N. Chen, C.N. Ma, M. Zhao and Y.J. Zhang \\ Department of Respiration, Huaihe Hospital of Henan University, Kaifeng, China \\ Corresponding author: Y.J. Zhang \\ E-mail: zhang_yj15@163.com \\ Genet. Mol. Res. 14 (4): 16006-16011 (2015) \\ Received June 25, 2015 \\ Accepted September 26, 2015 \\ Published December 7, 2015 \\ DOI http://dx.doi.org/10.4238/2015.December.7.13
}

\begin{abstract}
This report details a study conducted to assess the role of VEGF gene polymorphisms in the prognosis of advanced non-small cell lung carcinoma (NSCLC). Samples obtained from 210 advanced NSCLC patients admitted at the Huaihe Hospital of Henan University between January 2010 and December 2011 were recruited for this study. The VEGF -2578C/A (rs699947), +936C/T (rs3025039), and -634G/C (rs2010963) genotypes were analyzed by polymerase chain reaction-restriction fragment length polymorphism. We discovered, by logistic regression analysis, that the TT genotype of VEGF $+936 \mathrm{C} / \mathrm{T}$ was associated with more complete response + partial response to chemotherapy, compared to the CC genotype (odds ratio $(\mathrm{OR})=4.78,95 \%$ confidence interval $(\mathrm{Cl})=1.34-25.85)$. We also found a correlation between the TT genotype of VEGF $+936 \mathrm{C} / \mathrm{T}$ and lower risk of death from all causes compared to the CC genotype $(\mathrm{OR}=0.26,95 \% \mathrm{Cl}$ $=0.10-0.69$ ), using the Cox proportional hazard model (after adjusting for potential confounding factors). In conclusion, we discovered that the VEGF $+936 \mathrm{C} / \mathrm{T}$ gene polymorphism influences the response to chemotherapy and overall survival of NSCLC patients.
\end{abstract}

Key words: VEGF; Polymorphism; Non-small cell lung cancer; Clinical outcome 


\section{INTRODUCTION}

Lung cancer is the leading cause of cancer-related deaths worldwide, and is responsible for approximately 1.4 million deaths every year (Ferlay et al., 2008; Butts et al., 2014). A majority of the NSCLC patients are diagnosed during the advanced stages of the disease; in addition, a large number of those diagnosed during the early stages of the disease display eventual recurrence, metastatic disease, and overall poor prognosis (Gridelli et al., 2007). Platinum-based combination chemotherapy, which inhibits multiple biological pathways and mediates tumor growth, has been identified as an effective therapeutic strategy (Jung et al., 2002). The recent progress in research into vascular endothelial growth factors (VEGF) has paved the way for the development of therapeutic strategies against specific molecular targets that are of special interest in NSCLC (Boutsikou et al., 2013). Previous studies have reported a correlation between VEGF expression and poor prognosis of NSCLC, which revealed that the specific targeting of this pathway might have therapeutic significance (Yuan et al., 2001).

Several previous studies have reported an association between polymorphisms in the VEGF gene, and survival of advanced NSCLC; however, these results are inconsistent (Masago et al., 2009; Heist et al., 2008; Dong et al., 2010). Therefore, in this article we have reported a study assessing the role of VEGF gene polymorphisms in the prognosis of advanced NSCLC.

\section{MATERIAL AND METHODS}

\section{Patients}

A total of 210 advanced NSCLC patients admitted to our hospital between January 2010 and December 2011 were recruited to this study. The patients were recruited based on conformance with the following inclusion criteria: pathological- and radiological diagnosis of stage IIIB or IV, inoperable NSCLC; presence of tumors that could be measured by computerized tomography (CT) scanning; 18-75 years of age; and eastern cooperative oncology group (ECOG) performance status of $0-2$. The exclusion criteria included: ECOG performance status $>2$, severe clinical complications (cardiovascular and pulmonary diseases, bone marrow suppression, liver and renal dysfunctions, and/or organ failure), brain metastasis, a history of chemotherapy, and refusing to receive chemotherapy.

\section{Evaluation of clinical outcome}

The patients were requested to complete at least two cycles of chemotherapy, in order to evaluate the treatment response according to RECIST 1.1. The patients showing complete response $(C R)$ and partial response $(P R)$ were considered to be responding to chemotherapy, while those classified into the stable disease (SD) and progressive disease (PD) categories were regarded to be not responding to chemotherapy. The overall survival (OS) was defined as the period between the date of chemotherapy and the date of confirmed death (from any cause). Routine follow-ups of all patients were conducted up to January 2014.

\section{DNA extraction and genotyping}

Genomic DNA was isolated from peripheral blood lymphocytes (obtained from the patients), 
using the Qiagen Blood Mini kit (Qiagen, Venlo, Netherlands) as per the manufacturer protocols. The VEGF -2578C/A (rs699947), +936C/T (rs3025039), and -634G/C (rs2010963) genotypes were analyzed by polymerase chain reaction-restriction fragment length polymorphism (PCR-RFLP), according to instructions provided by the manufacturer. The primers and probes of VEGF -2578C/A (rs699947), +936C/T (rs3025039), and -634G/C (rs2010963) were designed using the Sequenom Assay Design 3.1 software. The PCR was set as follows: initial denaturation at $95^{\circ} \mathrm{C}$ for $5 \mathrm{~min}$, followed by 30 cycles of denaturation at $95^{\circ} \mathrm{C}$ for $30 \mathrm{~s}$, annealing at $59^{\circ} \mathrm{C}$ for $45 \mathrm{~s}$, and extension at $72^{\circ} \mathrm{C}$ for $30 \mathrm{~s}$, and a final extension at $72^{\circ} \mathrm{C}$ for $5 \mathrm{~min}$.

\section{Statistical analysis}

The clinical information is reported in the form of frequencies and percentage. The association between VEGF gene polymorphisms and response to chemotherapy was presented as the odds ratio $(\mathrm{OR})$ with $95 \%$ confidence interval $(\mathrm{Cl})$, in unconditioned logistic regression. Survival curves were analyzed by the Kaplan-Meier method, and the impact of polymorphisms in the VEGF gene on the OS was assessed using the log-rank test. The association between polymorphisms in the VEGF gene and OS was analyzed using the Cox proportional hazard model, and the results are reported as hazard ratio $(\mathrm{HR})$ and $95 \% \mathrm{Cl}$. The results were adjusted by baseline characteristics to avoid potential confounding effects. Two-sided $\mathrm{P}$ values $<0.05$ were considered to be statistical differences. The data was analyzed using the SPSS Statistics software (v.10.0; SPSS, Inc., Chicago, IL, USA).

\section{RESULTS}

The included NSCLC patients were characterized and distributed into groups, as summarized in Table 1. Seventy-nine (37.62\%) patients were above 65 years, and 131 (62.38\%) were below 65 years. One hundred and twenty-nine $(59.52 \%)$ NSCLC patients were males and 85 $(40.48 \%)$ were females, $102(48.57 \%)$ smoked tobacco, $75(35.71 \%)$ and $135(64.29 \%)$ were at the IIIB and IV stages of cancer, respectively, and $123(58.57 \%)$ and $87(41.41 \%)$ showed symptoms of adenocarcinoma NSCLC and squamous carcinoma, respectively.

\begin{tabular}{|c|c|c|}
\hline Variables & Cases & $\%$ \\
\hline \multicolumn{3}{|l|}{ Age (years) } \\
\hline$>65$ & 79 & 37.62 \\
\hline$\leq 65$ & 131 & 62.38 \\
\hline \multicolumn{3}{|l|}{ Gender } \\
\hline Female & 85 & 40.48 \\
\hline Male & 125 & 59.52 \\
\hline \multicolumn{3}{|l|}{ Tobacco smoking } \\
\hline Never & 108 & 51.43 \\
\hline Current or ever & 102 & 48.57 \\
\hline \multicolumn{3}{|l|}{ Stage } \\
\hline IIIB & 75 & 35.71 \\
\hline IV & 135 & 64.29 \\
\hline \multicolumn{3}{|l|}{ Histology } \\
\hline Adenocarcinoma & 123 & 58.57 \\
\hline Squamous carcinoma & 87 & 41.43 \\
\hline
\end{tabular}


During the follow-up period, 137 (65.24\%) NSCLC patients showed the CR+PR response to chemotherapy, while $73(34.76 \%)$ showed the SD+PD response. By logistic regression analysis, we discovered that the TT genotype of VEGF $+936 \mathrm{C} / \mathrm{T}$ was associated with greater CR+PR response to chemotherapy, compared to the $\mathrm{CC}$ genotype $(\mathrm{OR}=4.78,95 \% \mathrm{Cl}=1.34-25.85)$ (Table 2). However, we observed no significant correlations between VEGF -2578C/A and VEGF -634G/C gene polymorphisms and response to chemotherapy.

\begin{tabular}{|c|c|c|c|c|c|c|c|c|}
\hline Gene & Total & $\%$ & $\mathrm{CR}+\mathrm{PR}$ & $\%$ & SD+PD & $\%$ & OR $(95 \% \mathrm{Cl})^{1}$ & $P$ value \\
\hline \multicolumn{9}{|c|}{ VEGF -2578C/A } \\
\hline $\mathrm{CC}$ & 96 & 45.71 & 58 & 42.34 & 38 & 52.05 & 1.0 (Ref.) & - \\
\hline CA & 84 & 40.00 & 57 & 41.61 & 27 & 36.99 & $1.38(0.72-2.68)$ & 0.3 \\
\hline$A A$ & 30 & 14.29 & 22 & 16.06 & 8 & 10.96 & $1.80(0.68-5.16)$ & 0.2 \\
\hline \multicolumn{9}{|c|}{ VEGF $+936 \mathrm{C} / \mathrm{T}$} \\
\hline $\mathrm{CC}$ & 152 & 72.38 & 92 & 67.15 & 60 & 82.19 & 1.0 (Ref.) & - \\
\hline $\mathrm{CT}$ & 33 & 15.71 & 23 & 16.79 & 10 & 13.70 & $1.50(0.63-3.78)$ & 0.32 \\
\hline $\mathrm{TT}$ & 25 & 11.90 & 22 & 16.06 & 3 & 4.11 & $4.78(1.34-25.85)$ & 0.008 \\
\hline \multicolumn{9}{|c|}{ VEGF $-634 \mathrm{G} / \mathrm{C}$} \\
\hline GG & 79 & 37.62 & 50 & 36.50 & 29 & 39.73 & 1.0 (Ref.) & - \\
\hline GC & 111 & 52.86 & 73 & 53.28 & 38 & 52.05 & $1.11(0.58-2.12)$ & 0.72 \\
\hline $\mathrm{CC}$ & 20 & 9.52 & 14 & 10.22 & 6 & 8.22 & $1.35(0.43-4.77)$ & 0.58 \\
\hline
\end{tabular}

${ }^{1}$ Adjusted for age, gender, tobacco smoking, tumor stage, and histology.

One hundred and forty-six NSCLC patients died from varying causes at the end of the followup period; the five-year survival was $30.48 \%$. After adjusting for potential confounding factors in the Cox proportional hazards model, the TT genotype of VEGF +936C/T was found to be associated with lower risk of death from all causes, compared to the CC genotype. The HR $(95 \% \mathrm{Cl})$ for the TT genotype of VEGF +936C/T was $0.26(0.10-0.69)$ (Table 3). However, we observed no significant association between the polymorphisms in the VEGFs -2578C/A and -634G/C and OS in NSCLC patients.

\begin{tabular}{|c|c|c|c|c|c|c|c|c|}
\hline Gene & Total & $\%$ & Event & $\%$ & Alive & $\%$ & $\mathrm{HR}(95 \% \mathrm{Cl})^{1}$ & $P$ value \\
\hline \multicolumn{9}{|c|}{ VEGF $-2578 \mathrm{C} / \mathrm{A}$} \\
\hline $\mathrm{CC}$ & 96 & 45.71 & 69 & 47.26 & 27 & 42.19 & 1.0 (Ref.) & - \\
\hline $\mathrm{CA}$ & 84 & 40.0 & 57 & 39.04 & 27 & 42.19 & $0.83(0.42-1.65)$ & 0.56 \\
\hline AA & 30 & 14.29 & 20 & 13.70 & 10 & 15.63 & $0.78(0.30-2.13)$ & 0.58 \\
\hline \multicolumn{9}{|c|}{ VEGF $+936 \mathrm{C} / \mathrm{T}$} \\
\hline $\mathrm{CC}$ & 152 & 72.38 & 114 & 78.08 & 38 & 59.38 & 1.0 (Ref.) & - \\
\hline $\mathrm{CT}$ & 33 & 15.71 & 21 & 14.38 & 12 & 18.75 & $0.58(0.25-1.43)$ & 0.18 \\
\hline $\mathrm{TT}$ & 25 & 11.9 & 11 & 7.53 & 14 & 21.88 & $0.26(0.10-0.69)$ & 0.002 \\
\hline \multicolumn{9}{|c|}{ VEGF $-634 \mathrm{G} / \mathrm{C}$} \\
\hline GG & 79 & 37.62 & 59 & 40.41 & 20 & 31.25 & 1.0 (Ref.) & - \\
\hline GC & 111 & 52.86 & 75 & 51.37 & 36 & 56.25 & $0.71(0.35-1.41)$ & 0.29 \\
\hline $\mathrm{CC}$ & 20 & 9.52 & 12 & 8.22 & 8 & 12.50 & $0.51(0.16-1.66)$ & 0.19 \\
\hline
\end{tabular}

${ }^{1}$ Adjusted for age, gender, tobacco smoking, tumor stage, and histology.

\section{DISCUSSION}

In this study, the TT genotype of VEGF +936C/T was associated with a higher CR+PR response to chemotherapy. Compared to the $\mathrm{CC}$ genotype; this was correlated with a lower risk 
of death from all causes. A previous study reported that VEGF is a growth factor that regulates angiogenesis, and an important factor regulating the metastasis, survival, and spread of tumors. In addition, VEGF expression was reported to regulate tumor angiogenesis (Salven et al., 1997). The results of our study identified a correlation between polymorphisms in the VEGF +936C/T gene and a better response to chemotherapy and better clinical outcome of NSCLC.

Previous studies have reported an association between polymorphisms in the VEGF gene and response to chemotherapy and clinical outcome of several types of cancers, such as ovarian cancer, colorectal cancer, gastric cancer, osteosarcoma, and lung cancer (Steffensen et al., 2010; Hansen et al., 2011; Oh et al., 2013; Dong-Ju et al., 2014; Sohn et al., 2014; Tu et al., 2014). Steffensen et al. (2010) reported that VEGF gene polymorphisms were associated with the levels of serum VEGF, and the VEGF polymorphisms could influence the progression-free survival of ovarian cancer. Oh et al. (2013), in a study conducted in a Chinese population, discovered that genetic variations in the VEGF -634G/C gene were related to higher serum VEGF levels and poor clinical outcome in advanced gastric cancer patients. Another study conducted in Chinese osteosarcoma patients revealed that VEGF $-634 \mathrm{G} / \mathrm{C}$ and $+936 \mathrm{~T} / \mathrm{C}$ polymorphisms could affect the prognosis of osteosarcoma patients; in addition, these two gene polymorphisms are associated with decreased risk of death from osteosarcoma (Dong-Ju et al., 2014). However, other studies have reported inconsistent results. Tu et al. (2014) reported that VEGF $-2578 \mathrm{C} / \mathrm{A}$ and $-460 \mathrm{C} / \mathrm{T}$ was not associated with survival in lung cancer. The discrepancy in these above-mentioned results may be a result of differences in the type of tumor, selection of controls, sample size, or chance.

Several previous studies have reported inconsistent results associating polymorphisms in the VEGF gene and response to chemotherapy in NSCLC (Heist et al., 2008; Masago et al., 2009; Guan et al., 2010; Yin et al., 2012). One study, conducted in 124 Caucasian patients, did not find any significant association between VEGF +936T/C gene polymorphisms and overall survival of NSCLC (Guan et al., 2010). Heist et al. (2008) reported that VEGF +936C>T and $+405 G>C$ gene polymorphisms were associated with better survival of NSCLC; however, the -460T/C gene polymorphism was not associated with NSCLC survival (Heist et al., 2008). Yin et al. (2012), who conducted a study in an American population, found that VEGF $+936 \mathrm{C}>\mathrm{T},-460 \mathrm{C} / \mathrm{T}$ and $-634 \mathrm{G} /$ C gene polymorphisms could modulate the prognosis of NSCLC. However, in this study, the TT genotype of VEGF $+936 \mathrm{C} / \mathrm{T}$ was found to be associated with greater CR+PR response to chemotherapy, compared to the CC genotype; in addition, this was correlated with lower risk of death of NSCLC patients from all causes, compared to the CC genotype. Further studies are required to confirm our results.

In conclusion, the VEGF +936C/T gene polymorphism was found to influence the response to chemotherapy and overall survival of NSCLC patients. These findings may be useful in predicting the clinical outcome of patients with NSCLC. Further studies are required to confirm the clinical significance of these results.

\section{Conflicts of interest}

The authors declare no conflict of interest.

\section{ACKNOWLEDGMENTS}

We acknowledge the helps from nurses in Huaihe Hospital of Henan University for collecting blood samples and clinical characteristics of study subjects. 


\section{REFERENCES}

Boutsikou E, Kontakiotis T, Zarogoulidis P, Darwiche K, et al. (2013). Docetaxel-carboplatin in combination with erlotinib and/ or bevacizumab in patients with non-small cell lung cancer. OncoTargets Ther. 6: 125.

Butts C, Socinski MA, Mitchell PL, Thatcher N, et al. (2014). Tecemotide (L-BLP25) versus placebo after chemoradiotherapy for stage III non-small-cell lung cancer (START): a randomised, double-blind, phase 3 trial. Lancet Oncol. 15: 59-68.

Dong J, Dai J, Shu Y, Pan S, et al. (2010). Polymorphisms in EGFR and VEGF contribute to non-small-cell lung cancer survival in a Chinese population. Carcinogenesis 31: 1080-1086.

Dong-Ju Z, Ai-Ju X, Yun-Jiao T and Ming-Qiu Z (2014). Polymorphisms of vascular endothelial growth factor on prognosis in osteosarcoma patients. Pak. J. Med. Sci. 30: 1072-1076.

Ferlay J, Shin HR, Bray F, Forman D, et al. (2010). Estimates of worldwide burden of cancer in 2008: GLOBOCAN 2008. Int. J. Cancer 127: 2893-2917.

Gridelli C, Maione P, Rossi A and de Marinis F (2007). The role of bevacizumab in the treatment of non-small cell lung cancer: current indications and future developments. Oncologist 12: 1183-1193.

Guan X, Yin M, Wei Q, Zhao H, et al. (2010). Genotypes and haplotypes of the VEGF gene and survival in locally advanced non-small cell lung cancer patients treated with chemoradiotherapy. BMC Cancer 10: 431.

Hansen TF, Garm Spindler KL, Andersen RF, Lindebjerg J, et al. (2011). The predictive value of genetic variations in the vascular endothelial growth factor A gene in metastatic colorectal cancer. Pharmacogenomics J. 11: 53-60.

Heist RS, Zhai R, Liu G, Zhou W, et al. (2008). VEGF polymorphisms and survival in early-stage non-small-cell lung cancer. J. Clin. Oncol. 26: 856-862.

Jung YD, Mansfield PF, Akagi M, Takeda A, et al. (2002). Effects of combination antivascular endothelial growth factor receptor and anti-epidermal growth factor receptor therapies on the growth of gastric cancer in a nude mouse model. Eur. J. Cancer 38: 1133-1140.

Masago K, Fujita S, Kim YH, Hatachi Y, et al. (2009). Effect of vascular endothelial growth factor polymorphisms on survival in advanced-stage non-small-cell lung cancer. Cancer Sci. 100: 1917-1922.

Oh SY, Kwon HC, Kim SH, Lee S, et al. (2013). The relationship of vascular endothelial growth factor gene polymorphisms and clinical outcome in advanced gastric cancer patients treated with FOLFOX: VEGF polymorphism in gastric cancer. BMC Cancer 13: 43.

Salven P, Teerenhovi L and Joensuu H (1997). A high pre-treatment serum vascular endothelial growth factor concentration is associated with poor outcome in non-Hodgkin's lymphoma. Blood 90: 3167-3172.

Sohn BS, Park SJ, Kim JE, Kim KP, et al. (2014). Single-nucleotide polymorphisms in the vascular endothelial growth factor pathway and outcomes of patients treated with first-line cytotoxic chemotherapy combined with bevacizumab for advanced colorectal cancer. Oncology 87: 280-292.

Steffensen KD, Waldstrøm M, Brandslund I and Jakobsen A (2010). The relationship of VEGF polymorphisms with serum VEGF levels and progression-free survival in patients with epithelial ovarian cancer. Gynecol. Oncol. 117: 109-116.

Tu J, Wang S, Zhao J, Zhu J, et al. (2014). rs833061 and rs699947 on promoter gene of vascular endothelial growth factor (VEGF) and associated lung cancer susceptibility and survival: a meta-analysis. Med. Sci. Monit. 20: 2520-2526.

Yin M, Liao Z, Yuan X, Guan X, et al. (2012). Polymorphisms of the vascular endothelial growth factor gene and severe radiation pneumonitis in non-small cell lung cancer patients treated with definitive radiotherapy. Cancer Sci. 103: 945-950.

Yuan A, Yu CJ, Kuo SH, Chen WJ, et al. (2001) Vascular endothelial growth factor 189 mRNA isoform expression specifically correlates with tumor angiogenesis, patient survival, and postoperative relapse in non-small-cell lung cancer. J. Clin. Oncol. 19: 432-441. 